\title{
Patient-Reported Outcomes in Prostate Cancer: Prospective Changes Analysis for Prognosis Prediction
}

\author{
Teresa Sequeira ${ }^{1,2^{*}}$, Pedro Lopes Ferreira ${ }^{2,3}$, Joana Teixeira4, Isabel Peres ${ }^{5}$, Jorge Oliveira ${ }^{5}$, \\ Augusta Silveira ${ }^{1,2}$ \\ ${ }^{1}$ Fernando Pessoa University (UFP), Porto, Portugal \\ ${ }^{2}$ Centro de Estudos e Investigação em Saúde da Universidade de Coimbra (CEISUC), Coimbra, Portugal \\ ${ }^{3}$ Coimbra University, Coimbra, Portugal \\ ${ }^{4}$ Fernando Pessoa University Hospital School, Porto, Portugal \\ ${ }^{5}$ Instituto Português de Oncologia do Porto (IPOP), Porto, Portugal \\ Email: *teresas@ufp.edu.pt
}

Received 30 October 2015; accepted 13 December 2015; published 16 December 2015

Copyright (C) 2015 by authors and Scientific Research Publishing Inc.

This work is licensed under the Creative Commons Attribution International License (CC BY). http://creativecommons.org/licenses/by/4.0/

(c) (i) Open Access

\begin{abstract}
Prostate cancer is affecting a higher proportion of male population. Health Related Quality of Life assessment can guide the development of an interdisciplinary and patient-centered care intervention. This study is aimed to assess Health Related Quality of Life in prostate cancer patients. Relationships between socio-demographic, clinical characteristics and patient-reported outcomes have been considered. Consecutive outpatients with prostate cancer, admitted at the Urology Clinic of the Instituto Português de Oncologia do Porto, were studied $(n=300)$. Health Related Quality of Life was assessed as part of the routine practice. The European Organisation for Research and Treatment of Cancer general questionnaire, QLQ-C30, and its specific module for prostate cancer patients, QLQ-PR25, were used. Evolution along time (elapsed since diagnosis, and up to 5 years) was considered in order to search for a prognosis prediction in prostate cancer patients. This study confirms the feasibility of a systematic Health Related Quality of Life assessment. Global Health Related Quality of Life was found to be higher 6 months after diagnosis, decreasing then until the second year after diagnosis and improving thereafter. A peak with better scores was identified at the fifth year after diagnosis. Social and physical dimensions revealed a similar pattern. Clinical significance was found 6 months and 5 years after diagnosis. The prospective analysis of Health Related Quality of Life changes is able to explore the patients' outcomes in order to find patterns and relationships for prognosis prediction along the disease course. Such approach might promote patient confidence and thus a better cancer experience.
\end{abstract}

\footnotetext{
${ }^{*}$ Corresponding author.
}

How to cite this paper: Sequeira, T., Ferreira, P.L., Teixeira, J., Peres, I., Oliveira, J. and Silveira, A. (2015) Patient-Reported Outcomes in Prostate Cancer: Prospective Changes Analysis for Prognosis Prediction. Journal of Cancer Therapy, 6, 12381248. http://dx.doi.org/10.4236/jct.2015.615135 


\section{Keywords}

\section{Oncology, Prostate Cancer, Health Related Quality of Life, Patient-Reported Outcomes, Prognosis Prediction}

\section{Introduction}

Prostate cancer (PC) represents 12\% of all cancers in Europe being responsible for 1 in each 10 men's death caused by cancer in developed countries. The incidence rate for PC has increased since 1980. Worldwide, nearly 900,000 men were diagnosed with PC in 2008.

Literature reports higher incidence in Western countries and an increasing incidence trend in less developed countries. This behaviour is assigned to both prostate-specific antigen (PSA) screening availability and risk factors, such as diet, genetics, lifestyle and environmental factors. However, aetiological factors related to oncogenesis in PC remain unclear [1] [2].

PC is the second leading cause of cancer death in men, only exceeded by lung cancer. It is the most frequent tumour in men older than 50 years old, representing about 3.5\% of all global deaths and $10 \%$ of all cancer deaths in males. In a continuously aging population associated to an increasing life expectancy, the burden of prostate cancer is rising among older patients - currently, the median age at diagnosis is 68 years old. Despite all efforts, many patients are still diagnosed with the disease at an advanced stage [3] [4].

Though older people represent the majority of cancer patients, geriatric patients are often excluded from clinical trials. Evidence suggests that older patients experience worse toxicity when submitted to treatment intensification and may require more supportive care. However healthy senior adults have similar survival and treatment outcomes when compared with their younger peers [5]-[7].

Decision-making in oncology should be based on tumour characteristics; individual health status, and comorbidity, potential effects of treatment, patients' wishes and patient-reported outcomes assessment. Age per se should not be an exclusion criterion [4] [7] [8].

A comprehensive assessment should be incorporated when considering oncology research. Such assessment may signalize indicators that have the potential to guide oncologic care optimization, stratify patients into risk categories, and appear to have value as prognostic predicting outcome in cancer patients. Moreover, the survivors face physical, psychological, and social impairments that patient-reported outcomes can signalize [7]-[11].

The relationships between demographic, clinical characteristics and patient-reported outcomes have been evaluated in oncology. Health Related Quality of Life (HRQoL) measures and health utilities have been the focus [12]-[16].

Specific instruments for HRQoL assessment, especially for children and senior adults have been developed in order to comprehensively capture HRQoL symptoms and find specific groups' needs [17]-[19]. Longitudinal changes in physical function, symptom burden, and patients' HRQoL assessment can guide the development of an interdisciplinary and patient-centered care intervention [20].

\section{Objectives}

This study aimed to assess HRQoL in PC patients, in order to better understand the effects of cancer experience and its self-perception.

Additionally, we analysed HRQoL prospective evolution along different time intervals since diagnosis (up to 5 years) in order to search for a prognosis prediction in PC patients.

\section{Method}

\subsection{Ethics}

The study was carried out in compliance with the Helsinki Declaration. The method was previously approved by the local research ethical committee and all prostate cancer patients agreed to participate in the research and gave their informed consent. The data were collected for research purposes as part of the routine evaluation. 


\subsection{Patients}

From October 2014 to April 2015, consecutive outpatients with PC admitted at the Urology Clinic of Instituto Português de Oncologia do Porto (IPOP) were invited to participate in the HRQoL assessment protocol ( $\mathrm{n}=$ 300). All invited patients agreed to participate and questionnaires were completed immediately before consultation as a part of the routine evaluation. Inclusion criteria were: physical presence in IPOP for consultation in Urology Clinic, the ability to understand written and spoken Portuguese and provision of written consent.

\subsection{Socio-Demographic and Clinical Data}

Socio-demographic data—age, schooling years, address and marital status-were collected from the patient's clinical process and complemented, when needed, in semi structured interviews to patients or proxies.

Clinical data — family history of PC, time elapsed since diagnosis, tumour staging and last treatment—were considered and collected from the patient's clinical process and complemented, when needed, in semi structured interviews to clinical staff.

In order to understand the impact of disease course in HRQoL, patients were divided according to the time elapsed since diagnosis. Several periods since diagnosis were considered: $0 \mathrm{M}$-first medical consultation, $6 \mathrm{M}$ diagnosed up to 6 months, $1 \mathrm{Y}$-after six months of diagnosis and up to one year, $2 \mathrm{Y}$-after one year of diagnosis and up to 2 years, $5 \mathrm{Y}$-after two and up to 5 years of diagnosis, $10 \mathrm{Y}$-after five and up to ten years of diagnosis, more $10 \mathrm{Y}$ - diagnosed for more than ten years.

In order to understand HRQoL age-dependence, patients were divided into two groups: senior patients-SP (60 - 69 years old, $n=100)$ and geriatric patients-GP ( $\geq 70$ years old, $n=174)$.

\subsection{Questionnaires}

The European Organisation for Research and Treatment of Cancer (EORTC) cancer-specific HRQoL questionnaire-QLQ-C30, and its specific module for PC patients-QLQ-PR25, were used (Portuguese validated versions). The cancer-specific EORTC QLQ-C30 yields a global health status and five functioning scales (physical, role, social, emotional, and cognitive functions), three symptom scales (fatigue, nausea/vomiting and pain) and six single symptom items (dyspnea, insomnia, appetite loss, constipation, diarrhea and financial difficulties). The EORTC QLQ-PR25 contains two functioning scales (sexual functioning and sexual activity), three symptom scales (urinary symptoms/problems, bowel symptoms/problems, treatment-related symptoms, and a single symptom item (incontinence). All scales of the EORTC QLQ-C30 and the EORTC QLQ-PR25 range in score from 0 to 100. For functional scales and the global Quality of Life scale, a higher score represents a higher level of functioning or global Quality of Life. For symptom scales and single items, higher scores indicate more symptoms or more problems.

\subsection{Analysis Strategies and Statistics}

Completed questionnaires were scored according to EORTC instructions. HRQoL data were analyzed by the Statistical Package for Social Sciences (SPSS), version 17 for windows. Descriptive data are presented with means, standard deviations, medians, ranges, and proportions as appropriate.

\section{Results}

\section{1) Patients Characteristics}

Sociodemographic and clinical characteristics of the studied sample is presented in Table $1(n=300)$.

Three hundred patients with a mean age of $71.2 \pm 8.9$ years (range, 46 to 92 years) participated in this study by completing the questionnaires. Only $8.7 \%(n=26)$ were under 60 years.

Patients revealed a low educational level—only $9.0 \%$ completed 12 or more schooling years $(n=27)$. Most PC patients studied were married (80.7\%) and the vast majority revealed no PC family history (96.0\%) as depicted in Table 1.

When considering time elapsed since diagnosis, it was found that most patients (33.7\%) have been diagnosed for more than 2 and less than 5 years $(n=101)$.

It was found that primary tumor extension was ascribed to T2 or T3 for most patients (75.0\%) and lymph 
Table 1. Sociodemographic and clinical characteristics of the participants $(n=300)$.

\begin{tabular}{|c|c|c|}
\hline Categories & & $\%$ (n) \\
\hline \multirow[t]{5}{*}{ Age } & Under 60 & $8.7(26)$ \\
\hline & $60-69$ & $33.3(100)$ \\
\hline & $70-79$ & $40.3(121)$ \\
\hline & $80-89$ & $16.3(49)$ \\
\hline & $90+$ & $1.3(4)$ \\
\hline \multirow[t]{5}{*}{ Schooling (years) } & None & $2.0(6)$ \\
\hline & $1-4$ & $38.0(114)$ \\
\hline & $5-9$ & $34.0(102)$ \\
\hline & $10-12$ & $17.0(51)$ \\
\hline & $12+$ & $9.0(27)$ \\
\hline \multirow[t]{4}{*}{ Marital status } & Married & $80.7(242)$ \\
\hline & Widow & $17.7(53)$ \\
\hline & Divorced & $1.0(3)$ \\
\hline & Single & $0.7(2)$ \\
\hline PC family history & no & $96.0(288)$ \\
\hline \multirow[t]{7}{*}{ Time since diagnosis } & $0 \mathrm{M}$ & $9.0(27)$ \\
\hline & $6 \mathrm{M}$ & $3.3(10)$ \\
\hline & $1 \mathrm{Y}$ & $11.3(34)$ \\
\hline & $2 \mathrm{Y}$ & $14.3(43)$ \\
\hline & $5 \mathrm{Y}$ & $37.7(101)$ \\
\hline & $10 \mathrm{Y}$ & $17.7(53)$ \\
\hline & More $10 \mathrm{Y}$ & $10.7(32)$ \\
\hline \multirow[t]{11}{*}{ Tumor staging (TNM) } & Tx & $2.7(8)$ \\
\hline & $\mathrm{T} 1$ & $14.0(42)$ \\
\hline & $\mathrm{T} 2$ & $32.3(97)$ \\
\hline & T3 & $42.7(128)$ \\
\hline & Missings & $8.3(25)$ \\
\hline & $\mathrm{Nx}$ & $55.3(166)$ \\
\hline & No & 33.0 (99) \\
\hline & N1 & $0.7(2)$ \\
\hline & Missings & $11.0(33)$ \\
\hline & M0 & $94.7(284)$ \\
\hline & M1 & $5.3(16)$ \\
\hline \multirow[t]{5}{*}{ Last treatment } & Surgery & $38.3(115)$ \\
\hline & Radiotherapy & $27.0(81)$ \\
\hline & Hormone therapy & $27.0(81)$ \\
\hline & Brachytherapy & $5.3(16)$ \\
\hline & Chemotherapy & $2.3(7)$ \\
\hline
\end{tabular}


nodes could not be evaluated or were free of tumor cells for $88.3 \%$ of the studied sample $(n=275)$. Distant metastasis was ascribed to $5.3 \%$ of the patients as described in Table 1 .

Concerning last treatment carried out by PC patients it was observed that surgery, radiotherapy and hormone therapy were the most common treatments accomplished (Table 1).

2) HRQoL Evolution Considering Time Elapsed since Diagnosis

Figure 1(a) and Figure 1(b) illustrates the scores found concerning HRQoL.

Best scores were found 6 months and 5 years after diagnosis and worst scores were evident at 0 months and 2 years after diagnosis. Although no statistical difference was found-a considerable standard deviation was always present-changes revealing clinical significances were found concerning: global health status/QoL, for patients with 6 months, 2 and 5 years time after diagnosis (67.9\%, 56.6\% and 65.7\%, respectively); physical functioning, for patients with 6 months and 2 years time after diagnosis (90,5\% and 79.2\% respectively); social functioning, for patients with 6 months, 2 and 5 years time after diagnosis (95.2\%, 79.5\% and 90.7\%, respectively); fatigue, for patients with 6 months, 1,2 and 5 years time after diagnosis $(7.9 \%, 14.7 \%, 22.5 \%$ and $10.7 \%$, respectively); pain, for patients with 6 months, 1 and 2 years time after diagnosis $(7.1 \%, 14.7 \%$ and 16.7\%,

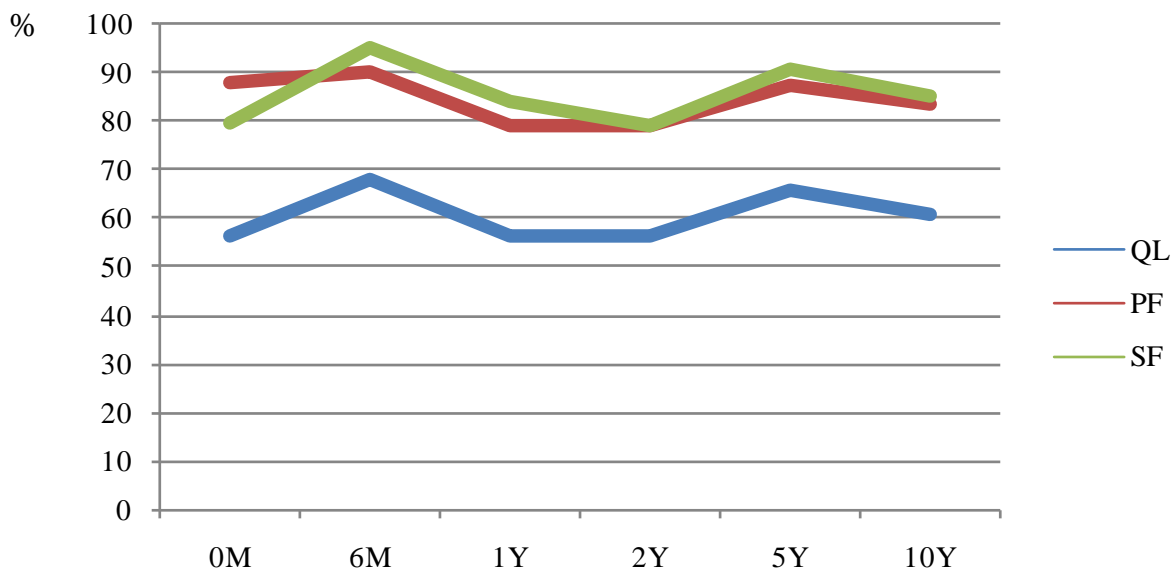

(a)

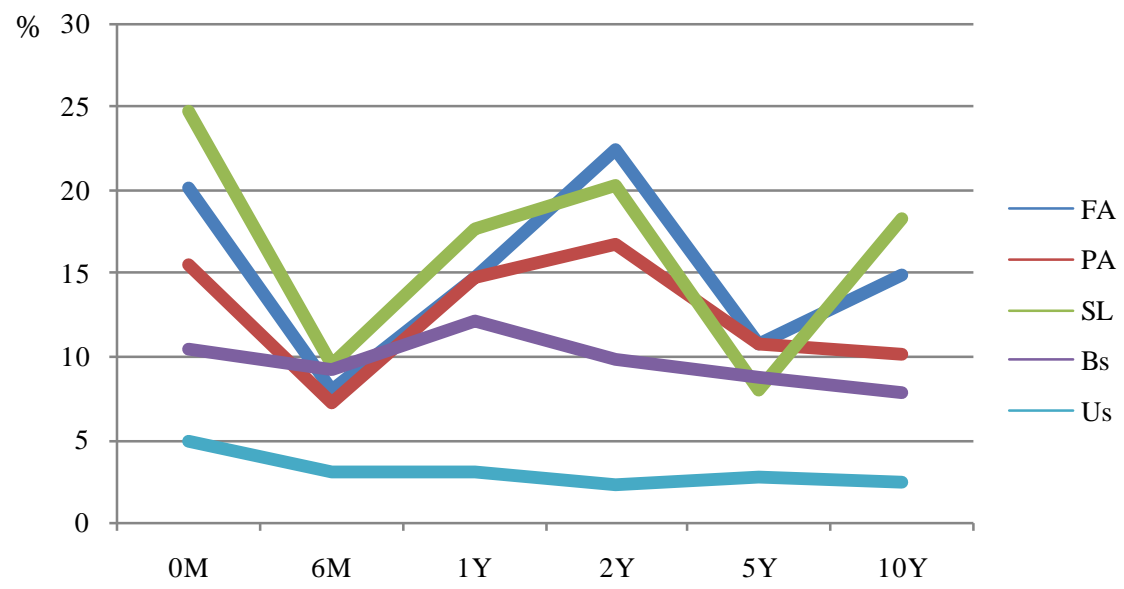

(b)

Figure 1. HRQoL scores found, expressed as a percentage, at different time intervals after diagnosis: $0 \mathrm{M}$-first medical consultation, $6 \mathrm{M}$-diagnosed up to 6 months, $1 \mathrm{Y}$-after six months after diagnosis and up to one year, $2 \mathrm{Y}$-after one year of diagnosis and up to 2 years, $5 \mathrm{Y}$-after two and up to 5 years after diagnosis, $10 \mathrm{Y}$-after five and up to ten years after diagnosis. (a) Global health status/ quality of life (QL), physical function (PF) and social function (SF), expressed as percentage (\%); (b) Symptoms scores found for fatigue (FA), pain (PA), insomnia (SL), bowel symptoms (Bs) and urinary symptoms (Us) expressed as percentage (\%). 
respectively); insomnia, for patients with 6 months, 2 and 5 years time after diagnosis (9.5\%, 20.2\% and 8.0\% respectively).

No statistical difference or clinical significance was found concerning urinary symptoms or bowel symptoms (scores ranging from $8.7 \%$ to $12.2 \%$ and $2.3 \%$ to $4.9 \%$, respectively) as illustrated in Figure 1(b).

Sexual activity and sexual functioning scores revealed to be quite constant (ranged from $90.6 \%$ to $94.2 \%$ and $25.0 \%$ to $29.5 \%$, respectively) did not present any clinical or statistical differences in the studied period and presented a high number of missing answers-data not shown.

3) Comparison with EORTC Reference Values

Figure 2(a) and Figure 2(b) illustrates the comparison between overall HRQoL values found $(\mathrm{n}=300)$ and EORTC reference values (all stages).

The studied sample revealed a lower score for global health status/QoL $(58.4 \%$ versus $68.4 \%, \mathrm{p}<0.01)$ and higher scores for emotional (79.9\% versus $76.6 \%$ ) and social functioning (83.0\% versus $80.2 \%)$, both with $\mathrm{p}<$ 0.05 (Figure 2(a)).

Favorable values were found in the studied sample for every symptom and single items ( $<<0.01)$ —exception made for appetite loss (found not different) and financial difficulties that revealed a higher score, $15.1 \%$ versus 9.0\% $(\mathrm{p}<0.01)$ (Figure 2(b)).

Figure 3(a) and Figure 3(b) depicts the comparison of senior's HRQoL (SP, 60 - 69 years old) with senior's EORTC reference values.

The SP population studied $(n=92)$ revealed to be different from EORTC reference values (60 - 69 years old) when considering global health status/QoL (58.5\% versus $69.8 \%, \mathrm{p}<0.01)$, emotional functioning $(72.2 \%$ versus $75.5 \%, \mathrm{p}<0.05)$, fatigue $(22.9 \%$ versus $25.2 \%, \mathrm{p}<0.01)$, pain $(22.2 \%$ versus $21.1 \%, \mathrm{p}<0.05)$, dyspnoea (9.0\% versus $15.3 \%, \mathrm{p}<0.01)$, insomnia ( $23.6 \%$ versus $25.2 \%, \mathrm{p}<0.01)$, constipation $(10.4 \%$ versus $12.6 \%$, $\mathrm{p}$ $<0.05$ ) and financial difficulties (20.8\% versus 10.4\%, p < 0.01) (Figure 3(a) and Figure 3(b)).

Figure 4(a) and Figure 4(b) illustrates the comparison of geriatric's HRQoL (GP, 70 and more years old) with EORTC reference values.

The GP studied population $(\mathrm{n}=102)$ revealed to be different from EORTC reference values (older than 70) when considering global health status/QoL (54.6\% versus $67.4 \%, \mathrm{p}<0.01)$, physical functioning $(75.7 \%$ versus $73.7 \%, \mathrm{p}<0.01)$, role functioning $(75.2 \%$ versus $79.5 \%, \mathrm{p}<0.05)$, emotional functioning $(75.0 \%$ versus $79.2 \%$, $\mathrm{p}<0.05)$, fatigue ( $25.5 \%$ versus $28.3 \%, \mathrm{p}<0.05)$, nausea $(2.5 \%$ versus $5.7 \%, \mathrm{p}<0.05)$, pain $(19.3 \%$ versus $24.8 \%, \mathrm{p}<0.01$ ), dyspnoea (9.5\% versus $19.5 \%$, $\mathrm{p}<0.01$ ), insomnia ( $24.5 \%$ versus $23.2 \%$, $\mathrm{p}<0.01$ ), constipation $(10.5 \%$ versus $17.3 \%, \mathrm{p}<0.01)$, diarrhoea $(4.2 \%$ versus $8.2 \%, \mathrm{p}<0.01)$ and financial difficulties $(17.0 \%$ versus 6.3\%, $\mathrm{p}<0.01$ ) - Figure 4(a) and Figure 4(b).

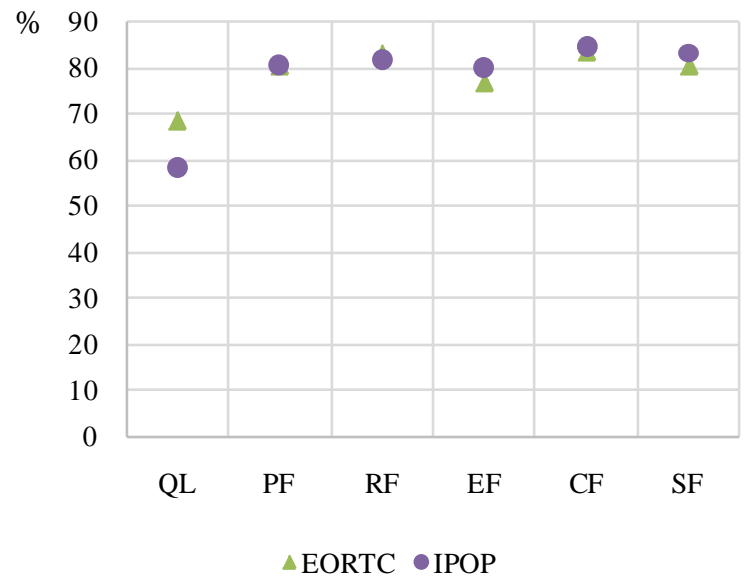

(a)

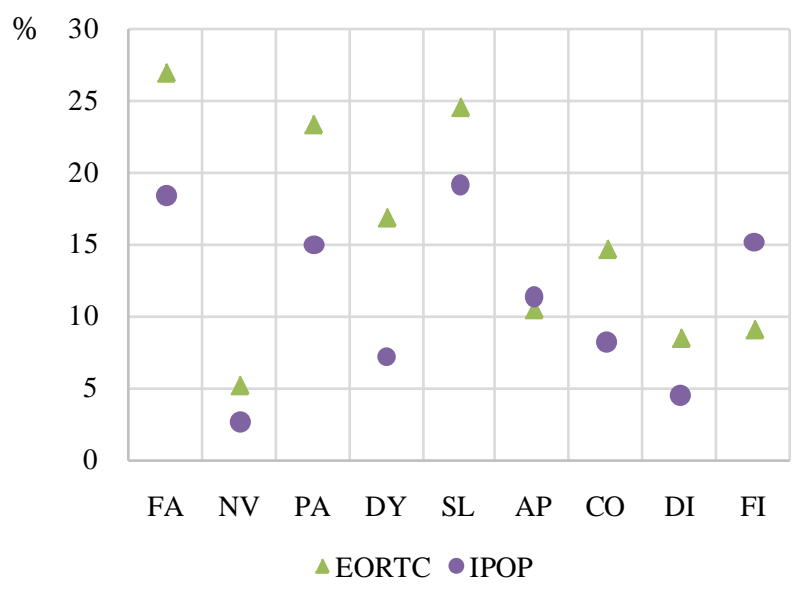

(b)

Figure 2. (a) Comparison between HRQoL and the functional scale values found in IPOP and EORTC reference values, expressed as percentages (QL, HRQoL; PF, physical functioning; RF, role functioning; EF, emotional functioning; CF, cognitive functioning; SF, social functioning); (b) Comparison between symptoms values found and EORTC reference values, expressed as percentages (FA, fatigue; NV, nausea; PA, pain; DY, dyspnoea; SL, insomnia; AP, appetite; CO, constipation; DI, diarrhoea; FI, financial). 


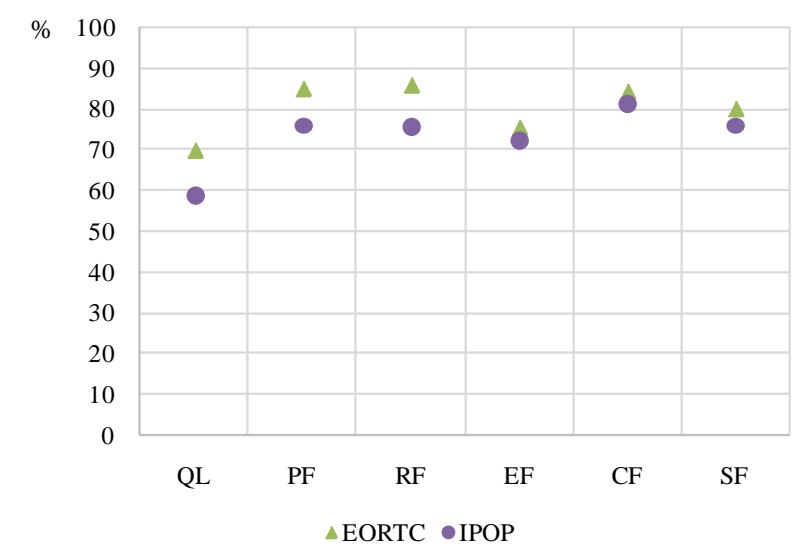

(a)

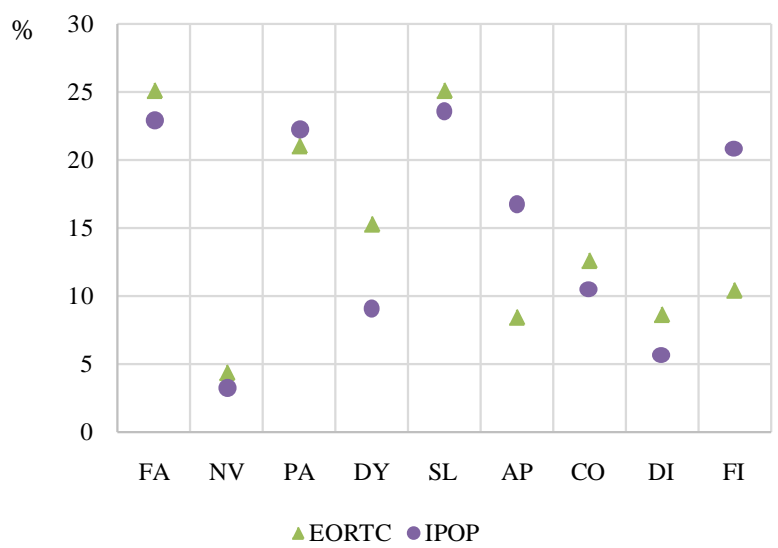

(b)

Figure 3. (a) Comparison of senior (60 - 69 years old) HRQoL and the functional scale values found in IPOP and EORTC reference values, expressed as percentages (QL, HRQoL; PF, physical functioning; RF, role functioning; EF, emotional functioning; CF, cognitive functioning; SF, social functioning); (b) Comparison of senior (60 - 69 years old) symptoms found and EORTC reference values, expressed as percentages (FA, fatigue; NV, nausea; PA, pain; DY, dyspnoea; SL, insomnia; AP, appetite; CO, constipation; DI, diarrhoea; FI, financial).

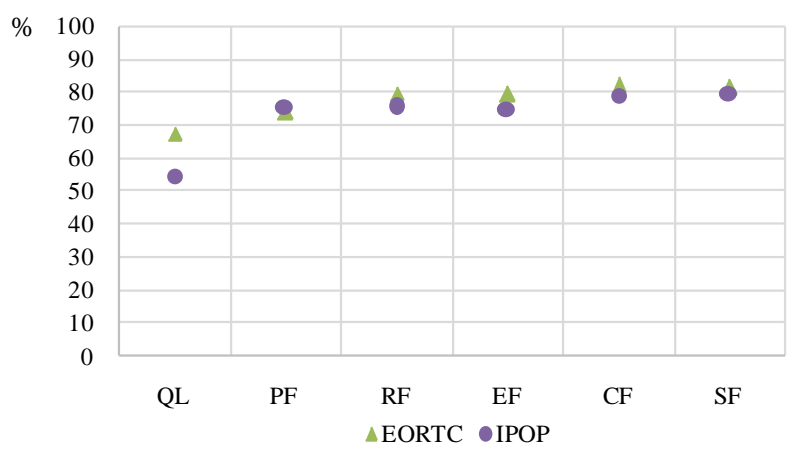

(a)

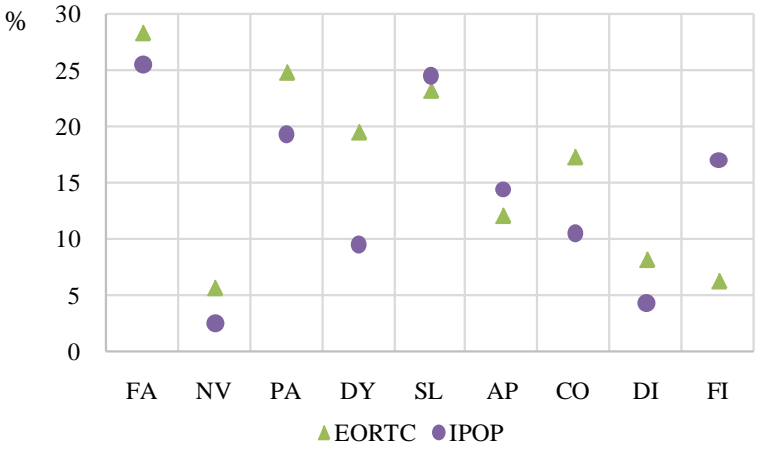

(b)

Figure 4. (a) Comparison of geriatric (70 years old and more) HRQoL and the functional scale values found in IPOP and EORTC reference values, expressed as percentages (QL, HRQoL; PF, physical functioning; RF, role functioning; EF, emotional functioning; CF, cognitive functioning; SF, social functioning); (b) Comparison of geriatric (70 years old and more) symptoms found and EORTC reference values, expressed as percentages (FA, fatigue; NV, nausea; PA, pain; DY, dyspnoea; SL, insomnia; AP, appetite; CO, constipation; DI, diarrhoea; FI, financial).

\section{Discussion}

PC is the second most common cancer worldwide and the most common in Europe amongst men, presenting a high incidence and a large geographical variation [21].

PC in IPOP (receiving oncologic patients from all north districts of Portugal) is the most common cancer in men with a percentage of 19.5 followed by colon cancer $(12.3 \%)$ and lung cancer (12.0\%). The incident rates in the country are heterogeneous considering different districts and range between 91.9 and 158.8/100,000 inhabitants (Porto and Viana do Castelo districts, respectively) being the difference statistically significant [22] [23]. IPOP projects an overall incident rate decrease for 2015 (91.7 against 95.8, last found in 2008), and expects an increase in younger patient's incidence (under 64 years old). The studied sample did not reflect such trend, once the percentage of prostatic patients found under 60 years old (8.7\%) was lower than the percentage found in 2008, 17.9\% [24].

We found that $40 \%$ of the patients had no more than 4 schooling years and despite low cases of regional or systemic metastasis founded, our sample presented T2 e T3 tumour stages preferentially (75\%). Illiterate men are considered to present a higher risk of being diagnosed in more advanced stages and having thus potentially more aggressive PC. The literature discusses the value of education for PC screening, diagnosis and informed 
decision among patients with lower literacy. The studied population could benefit with such sort of interventions [25] [26].

Most PC patients studied were married. Marriage has being considering one of the most important types of social support, favouring biologic profiles. Marital status reveals to be crucial to boost survival and promote better cancer experience [27].

PC family history found was rare suggesting that these patients are leading probably with this pathology for the first time in their lives. With no other references, prognosis prediction models can help to better understand the crucial changes during the disease evolution.

\subsection{HRQoL Prospective Evolution Analysis along Five Years since Diagnosis}

A general global pattern concerning HRQoL scores along the time elapsed since diagnosis was found and a standard behaviour in some crucial dimensions: global HRQoL, social and physical scales, fatigue, pain and insomnia symptoms.

Global HRQoL was found to be higher at 6 months after diagnosis, but decreased thereafter until the second year after diagnosis. Global HRQoL scale started then to improve and a peak was identified five years after diagnosis. Social and physical dimensions revealed a similar pattern. Clinical significance was also found at 6 month and 5 years since diagnosis, presenting better results. The pattern found may be related to crucial moments such as the decrease of the therapy's intensity in the early stages after diagnosis and the 5-year survival moment, allied to a possibility of clinical cure.

A clear negative impact was observed 2 years after diagnosis, when considering physical and social functioning, fatigue and pain. Therapy for PC often promotes loss of muscle mass, diminished muscle strength, increases fat mass and central adiposity, improving the loss of physical performance and earlier fatigue [28] [29]. These findings may explain worse HRQoL, affecting particularly the physical function and the fatigue symptom. Being pain one of the features cancer patients fear the most-its effective control is thus a critical issue. Pain persistence may have physical, social and psychological effects. Social isolation, concerns about losing intimate relationships and diminished sense of manhood are considered when social domains are discussed. Anxiety, fear, tension and depression are reflected in social scores and global HRQoL [30].

We found a clear relationship between the different scale scores and simple items that seem to influence each other. These outcomes are comprehensible: more pain and fatigue self-perception can promote lack of physical robustness and social isolation.

Sexual function did not present clinical or statistical differences along the studied period. Cultural issues related to privacy preservation may justify our sexual function scores. Indeed, PC patients often experience distressing sexual effects resulting in a range of sexual problem—-however most patients did not report any sexual bother [31] [32].

Urinary dysfunction in PC is a frequent problem. It includes incontinence, increased urinary frequency or urgency, pain upon urination, obstruction or irritating voiding symptoms. These clinical manifestations are common in PC patients and the impact of these symptoms in HRQoL depends on their baseline levels and clinical support [31] [32].

Our results point that "sexual function" and "urinary symptoms" seems to be controlled, presenting better scores when compared with other symptoms. The PC patients' baseline levels and clinical support patients experience during such period may thus contribute to increase the ability to manage this distress [31] [32].

HRQoL assessment allows prospective changes analysis in PC patients. These outcomes can provide precious information to better understand the patient evolution and prognosis. We recognize the heterogeneity of the PC studied patients-a future longitudinal prospective analysis will contribute to a more comprehensive clarification how the disease affects HRQoL. Accurate assessment of HRQoL is critical to management of cancer-related symptoms, patient counseling as well as to the decision making process [33].

\subsection{Comparison of HRQoL Results in This Group with the EORTC Reference Values}

Globally, the studied group revealed similar scores when compared with EORTC reference values. The IPOP scores found were close to EORTC's when considering HRQoL scale, physical functioning, role functioning, emotional functioning, cognitive functioning and social functioning. For fatigue, nausea, pain, dyspnoea, insomnia, constipation and diarrhoea, the IPOP revealed better scores. Interestingly, largest differences were observed 
in older patients. Such results may reflect the investment made in the Urology Clinic in recent years, investing in its assistance activity such as clinical staff training allied to patient involvement in decision making processsuch improvements are considered to be crucial for supporting best practices in PC healthcare, providing a good patient experience and optimizing the PC patients HRQoL [34] [35].

In opposite, the financial item revealed the major difference among samples being the worse score was found in our population. This finding may be explained by the fact that these PC patients have faced an important economical crisis affecting their country for at least 2 years.

\section{Conclusions}

Quality of life optimization and survival rates improvement are emphasized when early diagnosis and oncology treatments are considered.

All PC patients studied were included in HRQoL routine clinical assessment in IPOP. The evaluated cancer patients revealed higher HRQoL scores when compared with the literature suggesting that HRQoL routine evaluation (and its integration in the clinical process) can really optimize healthcare as a function of real time patient's perceptions. The inclusion of the patient-reported outcomes in the clinical process-allied to a prepared and sensitized clinical staff — can improve decision making and HRQoL optimization.

A prospective analysis supported by HRQoL evolution is able to explore patient self-perceptions in order to find patterns and relationships between simple items and scales. It might be useful for prognosis prediction in different moments, promoting the patient confidence and thus a better cancer experience.

\subsection{Research Implications}

HRQoL assessment in clinical practice is not common worldwide. HRQoL evaluation is crucial for institutions such as IPOP that receives 10,000 oncological patients/year. HRQoL is an increasingly prominent health marker in PC. The IPOP experienced routine HRQoL assessment implementation in Urology Clinic and uses the patientreported outcomes in clinical practice-involvement of physicians and nurses is critical to the process.

\subsection{Clinical Implications}

All PC patients can be evaluated whenever routine HRQoL assessment is implemented. A patient's reported outcome may contribute to supporting clinical decisions, identifying unmet needs and can be explored in routine care appointments supporting a stepped care model.

\section{Acknowledgements}

We acknowledge Caloust Gulbenkian Foundation for the support. We also acknowledge the IPOP's Urology Clinic for their generous collaboration, all health professionals involved and all the people who have voluntarily collaborated in the study.

\section{References}

[1] Baade, P.D., Youlden, D.R., Cramb, S.M., Dunn, J. and Gardiner, R.A. (2013) Epidemiology of Prostate Cancer in the Asia-Pacific Region. Prostate International, 1, 47-58. http://dx.doi.org/10.12954/PI.12014

[2] Center, M.M, Jemal, A., Lortet-Tieulent, J., Ward, E., Ferlay, J., Brawley, O., et al. (2012) International Variation in Prostate Cancer Incidence and Mortality Rates. European Urology, 61, 1079-1092. http://dx.doi.org/10.1016/j.eururo.2012.02.054

[3] Kessler, E.R. and Flaig, T.W. (2014) Geriatric Considerations in the Treatment of Advanced Prostate Cancer. F1000 Prime Reports, 6, 33.

[4] Droz, J.P., Balducci, L., Bolla, M., Emberton, M., Fitzpatrick, J.M., Joniau, S., Kattan, M.W., Monfardini, S., Moul, J.W., Naeim, A., van Poppel, H., Saad, F. and Sternberg, C.N. (2010) Management of Prostate Cancer in Older Men: Recommendations of a Working Group of the International Society of Geriatric Oncology. BJU International, 106, 462-469. http://dx.doi.org/10.1111/j.1464-410X.2010.09334.x

[5] Vander Walde, N.A., Fleming, M., Weiss, J. and Chera, B.S. (2013) Treatment of Older Patients with Head and Neck Cancer: A Review. Oncologist, 18, 568-578. http://dx.doi.org/10.1634/theoncologist.2012-0427

[6] Droz, J.P. and Chaladaj, A. (2008) Management of Metastatic Prostate Cancer: The Crucial Role of Geriatric Assess- 
ment. BJU International, 101, 23-29. http://dx.doi.org/10.1634/theoncologist.2012-0427

[7] Silveira, A., Gonçalves, J., Sequeira, T., Ribeiro, C., Lopes, C., Monteiro, E. and Pimentel, F.L. (2011) Geriatric Oncology: Comparing Health Related Quality of Life in Head and Neck Cancer Patients. Head \& Neck Oncology, 3, 3. http://dx.doi.org/10.1186/1758-3284-3-3

[8] Kordatou, Z., Kountourakis, P. and Papamichael, D. (2014) Treatment of Older Patients with Colorectal Cancer: A Perspective Review. Therapeutic Advances in Medical Oncology, 6, 128-140. http://dx.doi.org/10.1177/1758834014523328

[9] Williams, G.R., Deal, A.M., Jolly, T.A., Alston, S.M., Gordon, B.B., Dixon, S.A., Olajide, O.A., Chris Taylor, W., Messino, M.J. and Muss, H.B. (2014) Feasibility of Geriatric Assessment in Community Oncology Clinics. Journal of Geriatric Oncology, 5, 245-251. http://dx.doi.org/10.1016/j.jgo.2014.03.001

[10] Hamaker, M.E., Vos, A.G., Smorenburg, C.H., de Rooij, S.E. and van Munster, B.C. (2012) The Value of Geriatric Assessments in Predicting Treatment Tolerance and All-Cause Mortality in Older Patients with Cancer. Oncologist, 17, 1439-1449. http://dx.doi.org/10.1634/theoncologist.2012-0186

[11] Mohile, S., Dale, W. and Hurria, A. (2012) Geriatric Oncology Research to Improve Clinical Care. Nature Reviews Clinical Oncology, 9, 571-578. http://dx.doi.org/10.1038/nrclinonc.2012.125

[12] Green, L.E., Dinh, T.A., Hinds, D.A., Walser, B.L. and Allman, R. (2014) Economic Evaluation of Using a Genetic Test to Direct Breast Cancer Chemoprevention in White Women with a Previous Breast Biopsy. Applied Health Economics and Health Policy, 12, 203-217. http://dx.doi.org/10.1007/s40258-014-0089-6

[13] Hofs, K., Bjordal, K., Diep, L.M. and Rustøen, T. (2014) The Relationships between Demographic and Clinical Characteristics and Quality of Life during and after Radiotherapy: In Women with Breast Cancer. Quality of Life Research, 23, 2769-2777. http://dx.doi.org/10.1007/s11136-014-0736-2

[14] Song, L., Ji, Y. and Nielsen, M.E. (2014) Quality of Life and Health Status among Prostate Cancer Survivors and Noncancer Population Controls. Urology, 83, 658-663. http://dx.doi.org/10.1016/j.urology.2013.12.009

[15] Ferreira, P.L., Ferreira, L.N. and Pereira, L.N. (2013) Contribution for the Validation of the Portuguese Version of EQ-5D. Acta Médica Portuguesa, 26, 664-675.

[16] Silveira, A., Gonçalves, J., Sequeira, T., Ribeiro, C., Lopes, C., Monteiro, E. and Pimentel, F.L. (2012) Head and Neck Cancer: Health Related Quality of Life Assessment Considering Clinical and Epidemiological Perspectives. Revista Brasileira de Epidemiologia, 15, 38-48. http://dx.doi.org/10.1590/S1415-790X2012000100004

[17] Cataudella, D., Morley, T.E., Nesin, A., Fernandez, C.V., Johnston, D.L., Sung, L. and Zelcer, S. (2014) Development of a Quality of Life Instrument for Children with Advanced Cancer: The Pediatric Advanced Care Quality of Life Scale (PAC-QoL). Pediatric Blood \& Cancer, 61, 1840-1845. http://dx.doi.org/10.1002/pbc.25115

[18] Wilcox, C.B., Gilbourd, D. and Louie-Johnsun, M. (2014) Anxiety and Health-Related Quality of Life (HRQL) in Patients Undergoing Active Surveillance of Prostate Cancer in an Australian Centre. BJU International, 113, 64-68. http://dx.doi.org/10.1111/bju.12557

[19] Wheelwright, S., Darlington, A.S., Fitzsimmons, D., Fayers, P., Arraras, J.I., Bonnetain, F., Brain, E., Bredart, A., Chie, W.C., Giesinger, J., Hammerlid, E., O’Connor, S.J., Oerlemans, S., Pallis, A., Reed, M., Singhal, N., Vassiliou, V., Young, T. and Johnson, C. (2013) International Validation of the EORTC QLQ-ELD14 Questionnaire for Assessment of Health-Related Quality of Life Elderly Patients with Cancer. British Journal of Cancer, 109, 852-858. http://dx.doi.org/10.1038/bjc.2013.407

[20] Koczywas, M., Williams, A.C., Cristea, M., Reckamp, K., Grannis Jr., F.W., Tiep, B.L., Uman, G. and Ferrell, B. (2013) Longitudinal Changes in Function, Symptom Burden, and Quality of Life in Patients with Early-Stage Lung Cancer. Annals of Surgical Oncology, 20, 1788-1797. http://dx.doi.org/10.1245/s10434-012-2741-4

[21] Bray, F., Lortet-Tieulent, J., Ferlay, J., Forman, D. and Auvinen, A. (2010) Prostate Cancer Incidence and Mortality Trends in 37 European Countries: An Overview. European Journal of Cancer, 46, 3040-3052. http://dx.doi.org/10.1016/j.ejca.2010.09.013

[22] Neppl-Huber, C., Zappa, M., Coebergh, J.W., Rapiti, E., Rachtan, J., Holleczek, B., Rosso, S., Aareleid, T., Brenner, H. and Gondos, A., EUNICE Survival Working Group (2012) Changes in Incidence, Survival and Mortality of Prostate Cancer in Europe and the United States in the PSA Era: Additional Diagnoses and Avoided Deaths. Annals of Oncology, 23, 1325-1334. http://dx.doi.org/10.1093/annonc/mdr414

[23] RORENO (2008). http://www.roreno.com.pt/images/stories/pdfs/publ_roreno2008.pdf

[24] Projeções de Incidência de cancro região Norte—2013, 2015 e 2020. http://www.roreno.com.pt/images/stories/pdfs/publ_projecoes.pdf

[25] Tobias-Machado, M., Carvalhal, G.F., Freitas Jr., C.H., Reis, R.B., Reis, L.O., Nogueira, L., Machado, R.D., Magnabosco, W., Vieira, R.A.C., Mauad, E.C., Carvalho, A.L. and Faria, E.F., Cooperative Brazilian Uro-Oncology Group (CBUG) (2013) Association between Literacy, Compliance with Prostate Cancer Screening, and Cancer Ag- 
gressiveness: Results from a Brazilian Screening Study. International Braz J Urol, 39, 328-334. http://dx.doi.org/10.1590/S1677-5538.IBJU.2013.03.05

[26] Volka, R.J., Jibaja-Weissa, M.L., Hawleyb, S.T., Kneuperc, S., Spannc, S.J., Milesd, B.J. and Hymanc, D.J. (2008) Entertainment Education for Prostate Cancer Screening: A Randomized Trial among Primary Care Patients with Low Health Literacy. Patient Education and Counseling, 73, 482-489. http://dx.doi.org/10.1016/j.pec.2008.07.033

[27] Tyson, M., Andrews, P., Etzioni, D., Ferrigni, R., Humphreys, M., Swanson, S. and Castle, E. (2012) Marital Status and Prostate Cancer Outcomes. American Urological Association Annual Meeting, Atlanta, 19-23 May 2012, Abstract 171. http://dx.doi.org/10.1016/j.juro.2012.02.222

[28] Segal, R. (2014) Physical Functioning for Prostate Health. Canadian Urological Association Journal, 8, S162-S163. http://dx.doi.org/10.5489/cuaj.2315

[29] Storer, T.W., Miciek, R. and Travison, T.G. (2012) Muscle Function, Physical Performance and Body Composition Changes in Men with Prostate Cancer Undergoing Androgen Deprivation Therapy. Asian Journal of Andrology, 14, 204-221. http://dx.doi.org/10.1038/aja.2011.104

[30] Campbell, L.C., Keefe, F.J., McKee, D.C., Waters, S.J. and Moul, J.W. (2012) Masculinity Beliefs Predict Psychosocial Functioning in African American Prostate Cancer Survivors. American Journal of Men's Health, 6, 400-408. http://dx.doi.org/10.1177/1557988312450185

[31] Benedict, C., Traeger, L., Dahn, J.R., Antoni, M., Zhou, E.S., Bustillo, N. and Penedo, F.J. (2014) Sexual Bother in Men with Advanced Prostate Cancer Undergoing Androgen Deprivation Therapy. The Journal of Sexual Medicine, 11, 2571-2580. http://dx.doi.org/10.1111/jsm.12645

[32] Kato, T., Komiya, A., Suzuki, H., Imamoto, T., Ueda, T. and Ichikawa, T. (2007) Effect of Androgen Deprivation Therapy on Quality of Life in Japanese Men with Prostate Cancer. International Journal of Urology, 14, 416-421. http://dx.doi.org/10.1111/j.1442-2042.2007.01748.x

[33] Torvinen, S., Farkkila, N., Sintonen, H., Saarto, T., Roine, R.P. and Taari, K. (2013) Health-Related Quality of Life in Prostate Cancer. Acta Oncologica, 52, 1094-1101. http://dx.doi.org/10.3109/0284186X.2012.760848

[34] Ahmed, F., Burt, J. and Roland, M. (2014) Measuring Patient Experience: Concepts and Methods. The Patient- Patient-Centered Outcomes Research, 7, 235-241. http://dx.doi.org/10.1007/s40271-014-0060-5

[35] Karnon, J., Partington, A., Horsfall, M. and Chew, D. (2015) Variation in Clinical Practice: A Priority Setting Approach to the Staged Funding of Quality Improvement. Applied Health Economics and Health Policy. (In Press) http://dx.doi.org/10.1007/s40258-015-0160-y 